\title{
Generation of HIV-1 and Internal Control Transcripts as Standards for an In-House Quantitative Competitive RT-PCR Assay to Determine HIV-1 Viral Load
}

\author{
Anny Armas Cayarga, ${ }^{1}$ Yenitse Perea Hernández, ${ }^{1}$ Yaimé J. González González, ${ }^{1}$ \\ Santiago Dueñas Carrera, ${ }^{2}$ Idania González Pérez, ${ }^{1}$ and René Robaina Álvarez ${ }^{1}$ \\ ${ }^{1}$ Molecular Biology Department, Centro de InmunoEnsayo (CIE), Calle 134 y Avenida 25 Playa, Apartado Postal 6653, \\ Ciudad de la Habana, CP 11600, Cuba \\ ${ }^{2}$ HCV Department, Vaccine Division, Centro de Ingeniería Genética y Biotecnología (CIGB), Apartado Postal 6653, \\ Ciudad de la Habana, CP 10600, Cuba
}

Correspondence should be addressed to Anny Armas Cayarga, anny.armas@yahoo.com

Received 10 January 2011; Revised 19 April 2011; Accepted 27 April 2011

Academic Editor: Gabriel A. Monteiro

Copyright (c) 2011 Anny Armas Cayarga et al. This is an open access article distributed under the Creative Commons Attribution License, which permits unrestricted use, distribution, and reproduction in any medium, provided the original work is properly cited.

Human immunodeficiency virus type-1 (HIV-1) viral load is useful for monitoring disease progression in HIV-infected individuals. We generated RNA standards of HIV-1 and internal control (IC) by in vitro transcription and evaluated its performance in a quantitative reverse transcription polymerase chain reaction (qRT-PCR) assay. HIV-1 and IC standards were obtained at high RNA concentrations, without DNA contamination. When these transcripts were included as standards in a qRTPCR assay, it was obtained a good accuracy $\left( \pm 0.5 \log _{10}\right.$ unit of the expected results) in the quantification of the HIV-1 RNA international standard and controls. The lower limit detection achieved using these standards was $511.0 \mathrm{IU} / \mathrm{mL}$. A high correlation $(r=0.925)$ was obtained between the in-house qRT-PCR assay and the NucliSens easyQ HIV-1 test (bioMerieux) for HIV-1 RNA quantitation with clinical samples $(N=14)$. HIV-1 and IC RNA transcripts, generated in this study, proved to be useful as standards in an in-house qRT-PCR assay for determination of HIV-1 viral load.

\section{Introduction}

The quantitation of human immunodeficiency virus type1 (HIV-1) RNA is a crucial factor to help clinicians decide whether to stop or continue antiretroviral combinations after switching or starting antiretroviral drug therapy [1]. In addition, it is a useful biological marker to study HIV dynamics [2,3], host/virus interaction, HIV evolution, and the progression of the acquired immunodeficiency syndrome (AIDS) $[4,5]$.

There are three major methodologies available for viral load quantitation. The reverse transcriptase-polymerase chain reaction (RT-PCR), the nucleic acid sequence-based amplification (NASBA) and a signal amplification methodology termed branched-chain DNA (bDNA) technique [6]. In the past recent years there have been new reported viral load assays that have incorporated the real-time detection, such as the COBAS TaqMan HIV-1 test from Roche Diagnostics [7], which utilizes real-time PCR technology [8] and the NucliSens EasyQ HIV-1 from bioMerieux, which uses molecular beacon for the real-time detection [9]. In spite of the advantages that offer the use of the real-time PCR, which helps reducing the possibility of contamination, increasing the assay sensitivity, and improving the turnaround time [10], commercially available real-time PCR assays are just as expensive as the more standard nucleic acid viral load tests and also rely on expensive, often dedicated equipment, that can only be used for these assays $[10,11]$. For this reason, inexpensive and technologically simpler assays are still needed in resource-limited countries, where the new technology and equipments are currently not available.

For the development of an in-house quantitative competitive RT-PCR assay (qRT-PCR) for the estimation of HIV-1 viral load, it is necessary to obtain an HIV-1 RNA external 
TABLE 1: Sequences of the primers and probes used in this study.

\begin{tabular}{lclc}
\hline Code & Polarity $^{\mathrm{a}}$ & Primer or probe sequence $\left(5^{\prime}\right.$ to $\left.3^{\prime}\right)$ & Source \\
\hline Primer HIV1-Q3 & + & CTCAATAAAGCTTGCCTTGA & {$[15]$} \\
Primer HIV1-Biot-Q4 & - & GGGCGCCACTGCTAGAGA & {$[15]$} \\
Primer IC-1 & + & CTCAATAAAGCTTGCCTTGATAGTTGAATTGAAAGTGC & This study \\
Primer IC-2 & - & GGGCGCCACTGCTAGAGAATAGTGTCGCCCACGTTTAC & This study \\
T7 promoter primer & + & TAATACGACTCACTATAGGG & {$[16]$} \\
Probe HIV1-S & None & AGTAGTGTGTGCCCGTCTGT & {$[15]$} \\
Probe IC-S1 & None & TAGTTGAATTGAAAGTGCCCGACAT & This study \\
\hline
\end{tabular}

${ }^{a}$ Polarity: (+) sense, $(-)$ antisense.

control (calibration curve) and an internal quantitation control (IC), which is added to the specimen at a known concentration before RNA extraction. The IC can be differentiated from the viral target sequences and serves to compensate for variability in RNA extraction and also to indicate substances in serum or plasma that may be inhibitory to PCR amplification [12].

Although chemical synthesis up to a length of about 80 nucleotides is possible, yields decrease rapidly and costs become prohibitive. A good alternative is to produce the RNA by in vitro transcription with T7 RNA polymerase [13]. RNA synthesis by in vitro transcription using phage T7 RNA polymerase allows preparation of milligram quantities of RNA for biochemical, biophysical, and structural investigations [14].

In this study, we generated RNA standards with HIV-1 and internal control sequences, using in vitro transcription method and evaluated its performance in a qRT-PCR for determining HIV-1 viral load.

\section{Materials and Methods}

2.1. RNA Isolation. RNA was extracted from $200 \mu \mathrm{L}$ of human serum or plasma by the guanidinium isothiocyanateacid phenol method [17] with modifications [18]. The RNA pellets were resuspended in $20 \mu \mathrm{L}$ of diethylpyrocarbonate(DEPC-) treated water.

2.2. Amplification of HIV-1 RNA by RT-PCR. A fragment of $120 \mathrm{bp}$ located in the $5^{\prime}$ LTR region of the HIV-1 genome was amplified from RNA isolated from an HIV-1 subtypeB-infected serum, by RT-PCR. The cDNA synthesis by RT and amplification by PCR were carried out in a single tube in a reaction mixture of $25 \mu \mathrm{L}$ using $5 \mu \mathrm{L}$ of the isolated RNA. The reaction contained $25 \mathrm{pmol}$ of each of the primers HIV1-Q3 and HIV1-Biot-Q4 (Table 1) that correspond to the long terminal repeat (LTR) region of the HIV-1 genome, Go Taq buffer, $1.5 \mathrm{mM} \mathrm{MgCl}_{2}, 250 \mu \mathrm{M}$ of each dNTPs, $3.6 \mathrm{u}$ of AMV-RT, $9 \mathrm{u}$ of RNasin ribonuclease inhibitor, and $1.05 \mathrm{u}$ of Go Taq Flexi DNA polymerase (all from Promega, USA). The reaction was carried out in a thermocycler (Eppendorf, Hamburg, Germany). The amplified product was checked by hybridization using a probe complementary to the amplified HIV-1 fragment (HIV1-S) (Table 1).
2.3. Amplification of the Internal Control (IC) Fragment. A fragment of $120 \mathrm{bp}$ was amplified by PCR, from a plasmid that contained the sequence of the $\mathrm{p}-64 \mathrm{~K}$ protein of Neisseria meningitidis, flanked by the sequences of binding to sense and antisense primers (HIV1-Q3 and HIV1-Biot-Q4, resp.). The PCR reaction was done using the same conditions described above and the primers IC-1 and IC-2 (Table 1).

2.4. Cloning of the Amplified HIV-1 and IC Fragments into the pGEM-T Vector. The amplified HIV-1 and IC fragments were gel-purified using the Wizard SV Gel and PCR CleanUp System (Promega, USA) and cloned into the pGEM-T vector following the manufacturer's instructions (pGEM$\mathrm{T}$ and pGEM-T Easy Vector Systems, Promega, USA). Escherichia coli XL-1 blue cells were transformed with the products of the ligation reactions and plated on LuriaBertani- (LB-) ampicillin plate to select the transformed colonies. The plasmid DNA was isolated and purified from the colonies using the Wizard plus SV Minipreps DNA Purification System (Promega, USA), and PCR amplified to check the orientation of the cloned HIV-1 and IC fragments. The PCR reactions were performed using $25 \mathrm{pmol}$ of the T7 Promoter primer from Promega, USA (Table 1) and $25 \mathrm{pmol}$ of HIV1-Biot-Q4 primer. The correct orientation of the HIV1 and IC fragments into the pGEM-T vector must generate a PCR band of $189 \mathrm{bp}$.

2.5. In Vitro Transcription. Two batches of the pGEM-HIV1 and pGEM-IC plasmids were linearized with Mlu1 enzyme (Promega, USA). The correspondent HIV-1 and IC RNAs were obtained from $1 \mu \mathrm{g}$ of pGEM-HIV1 and pGEM-IC plasmids using $50 \mathrm{u}$ of T7 RNA polymerase (Promega, USA) in presence of $0.75 \mathrm{mM}$ of each rNTPs (Promega, USA), transcription buffer (Promega, USA) in a $50 \mu \mathrm{L}$ reaction, according to the procedure optimized in our laboratory, described in [19]. After transcription, 2 or $4 \mathrm{u}$ of RNase free DNase (Promega, USA) per $1 \mu \mathrm{g}$ of template DNA, were added for 15 or $30 \mathrm{~min}$ at $37^{\circ} \mathrm{C}$ to degrade the contaminant DNA. Finally, the HIV-1 and IC transcripts were purified by phenol-chloroform extraction and were precipitated with 2.5 volumes of ethanol 95\%. After RNA was washed and dried, it was dissolved in $50 \mu \mathrm{L}$ of DEPC-treated water. 


\subsection{Evaluation of the HIV-1 and IC Transcripts}

2.6.1. Determination of RNA Concentration by Optical Density Measuring. One aliquot of each purified HIV-1 and IC transcripts was diluted $1: 20$ or $1: 35$ with DEPC-treated water and quantitated by measuring the optical density $(\mathrm{OD})$ at $260 \mathrm{~nm}$ using the spectrophotometer (GeneQuant II, Pharmacia, USA). The ratio of absorbance at 260 and $280 \mathrm{~nm}$ was also obtained for the purified transcripts.

2.6.2. Evaluation of the Quality of the HIV-1 and IC Transcripts by Determining the Presence of RNA and DNA Contamination. The purified HIV-1 and IC transcripts were diluted $1: 4$ in a lysis reagent for preservation at $4{ }^{\circ} \mathrm{C}[20$, 21]. For the evaluation of the quality of the HIV-1 and IC transcripts, they were 10-fold serially diluted in lysis reagent from $1: 4 \times 10^{3}$ to $1: 4 \times 10^{9}$. Isolation of RNA from lysis reagent was performed as described above. In this case, the lysis reagent containing the HIV-1 and IC transcripts was used in a volume of $500 \mu \mathrm{L}$ per sample. To simulate the natural sample, in the case of transcripts diluted in lysis reagent, $200 \mu \mathrm{L}$ of cryosupernatant negative for hepatitis $\mathrm{C}$ virus (HCV), human immunodeficiency virus (HIV), and hepatitis B virus (HBV) were added to the mixture. The absence of plasmid template and the presence of RNA in the diluted HIV-1 and IC transcripts were verified through 50 cycles of PCR and RT-PCR, respectively, in mixes of $30 \mu \mathrm{L}$, employing HIV1-Q3 and HIV1-Biot-Q4 primers. Several negative and positive RT-PCR and PCR controls were tested. A HIV-, HCV- and HBV-negative cryosupernatant was used as a negative control of each assay. Positive HIV-1 RT-PCR control consisted on a positive HIV1 plasma sample while the positive HIV-1 and IC PCR controls were the same plasmids used as templates in the in vitro transcription reactions. The amplified products were checked by hybridization using probes complementary to HIV-1 (HIV1-S) and IC (IC-S1) fragments (Table 1).

2.6.3. Determination of the Working Dilution of the IC Transcript in an In-House Quantitative Competitive RT-PCR Assay. The dilution required for the IC transcript to work optimally as a competitor was determined by titration versus HIV-1positive human plasma calibration curves in a competitive RT-PCR assay described below. The calibration curve was obtained by diluting HIV-1-positive human plasma with high viral load, 10 -fold from $10^{6}$ to $10^{2} \mathrm{IU} / \mathrm{mL}$. As internal control, we evaluated four dilutions of the IC transcript, using the lysis reagent as diluent $\left(1: 4 \times 10^{4}, 1: 4 \times 10^{5}, 1: 4\right.$ $\times 10^{6}$ and $1: 4 \times 10^{7}$ ). Two HIV-1 RNA concentrations of the WHO international standard (IS) 97/656 (NIBSC, South Mimms, Potters Bar, Hertfordshire, UK) $10^{3}$ and $10^{4} \mathrm{IU} / \mathrm{mL}$ were evaluated in the same experiment. Previously, each vial of the international standard was reconstituted in $1 \mathrm{~mL}$ of ultrapure water as instructed by the NIBSC to yield a solution containing $10^{5} \mathrm{IU} / \mathrm{mL}$ of HIV-1 RNA. The determination coefficient $r^{2}$, the curve slope $(b)$ values, and the accuracy in the quantification of different HIV-1 RNA IS concentrations were taken into account to select the working dilution of the IC transcript.
2.6.4. Determination of the HIV-1 Transcript RNA Concentration. The RNA concentration of the HIV-1 transcript was determined through the qRT-PCR assay described below using a calibration curve built from the IS 97/650 (NIBSC, South Mimms, Potters Bar, Hertfordshire, UK). Each vial of the international standard was reconstituted in $1 \mathrm{~mL}$ of ultrapure water as instructed by the NIBSC to yield a solution containing $363078.05 \mathrm{IU} / \mathrm{mL}$ of HIV-1 RNA. It was diluted 10 -fold to obtain the calibration curve (363.08 to $363078.05 \mathrm{IU} / \mathrm{mL}$ ). Isolation of RNA from IS or lysis reagent containing the HIV-1 transcript was performed as described above. The lysis reagent containing the IC transcript in its working dilution was used in a volume of $500 \mu \mathrm{L}$ per sample. The HIV-1 transcript was 10-fold serially diluted from $1: 4 \times$ $10^{7}$ to $1: 4 \times 10^{11}$ in order to quantify it, and the RNA concentration of the original HIV-1 transcript (IU/mL) was obtained by averaging each value multiplied by the dilution factor. HIV-1 transcript dilutions, where the $R$ value was out of the calibration curve range, were considered non quantifiable.

2.6.5. Evaluation of the HIV-1 and IC Transcripts as Standards in an In-House qRT-PCR Assay for Estimation of HIV-1 Viral Load. For standardization of the assay, the HIV-1 and IC transcripts were included as standards in an inhouse quantitative competitive RT-PCR assay for estimation of HIV-1 viral load. The IC transcript is a 120-bp RNA fragment, which is similar to the HIV-1 target except for a short and unique internal sequence. This transcript is added to the specimen during sample preparation and is simultaneously amplified by PCR in a competitive reaction. The IC transcript was used into the lysis reagent in its working dilution. In order to build the calibration curve, dilutions of the HIV-1 transcript were made to give $10^{3}, 10^{4}, 10^{5}, 10^{6}$, and $10^{7} \mathrm{IU} / \mathrm{mL}$ of HIV-1 RNA. The IS was evaluated pure, $1: 10$, and $1: 100$, and also two samples with very high viral load (HIV1-235 and HIV1-157), previously quantified by the NucliSens EasyQ HIV-1 v1.1 assay (bioMerieux, Boxtel, The Netherlands), were evaluated. Different parameters such as the determination of coefficient $r^{2}$ and the accuracy in the quantification of the HIV-1 RNA IS and the two reference samples were measured.

2.7. Description of the In-House qRT-PCR Assay. Following sample preparation and setup of the reaction mixture, reverse transcription and amplification of the target and the internal control were simultaneously performed in the same reaction tube. We added $5 \mu \mathrm{L}$ of the isolated RNA to $25 \mu \mathrm{L}$ of an RT-PCR reaction mixture that contained 50 pmol of the HIV1-Q3 and HIV1-Biot-Q4 primers, Go Taq buffer, $1.5 \mathrm{mM} \mathrm{MgCl} 2,250 \mu \mathrm{M}$ each dNTPs, $3.6 \mathrm{u}$ of AMV-RT, $9 \mathrm{u}$ of RNasin ribonuclease inhibitor, and $1.05 \mathrm{u}$ of Go Taq Flexi DNA polymerase (all from Promega, USA). These reactions were carried out in a thermocycler (Eppendorf AG 22331, Hamburg, Germany) at $45^{\circ} \mathrm{C}$ for $30 \mathrm{~min}$ followed by $95^{\circ} \mathrm{C}$ for $3 \mathrm{~min}$ and 50 cycles at $95^{\circ} \mathrm{C}$ for $30 \mathrm{~s}, 58^{\circ} \mathrm{C}$ for $30 \mathrm{~s}$, and $72^{\circ} \mathrm{C}$ for $30 \mathrm{~s}$. The hybridization and detection of the amplified products were done in 
the ultramicroenzyme-linked oligosorbent assay (UMELOSA) format [22]. It is a detection system similar to the one used by the Amplicor HIV-1 Monitor Test v1.5, from Roche Diagnostic Systems (Branchburg, NJ, USA) [23], but unlike the colorimetric reaction, we use a fluorescence reading. Following PCR amplification, the HIV-1 and IC amplicons were chemically denatured by the addition of denaturation solution. Aliquots were added, in duplicate, to separate wells of a microwell plate coated with HIV-1-specific (HIV1-S) an IC-specific (IC-S1) probes. HIV-1 and IC amplification products were bound to HIV-1 and IC wells, respectively, by hybridization to the microwell plate-bound probes. Following the hybridization reaction, the microwell plate was washed to remove unbound material and a streptavidinalkaline phosphatase conjugate was added to each well of the plate. The conjugate bound to the biotin-labeled amplicon captured by the plate-bound probes. The plate was washed again to remove unbound conjugate, and a substrate 4Methylumbelliferyl phosphate (4-MUP) was added to the wells. In the presence of this fluorescent substrate, the bound alkaline phosphatase catalyzes the hydrolysis of 4-MUP to produce a fluorescent signal that is detected by an automated microwell plate reader.

The calibration curve, made from HIV-1 reference sample, HIV-1 IS or HIV-1 transcript, was built by weighted linear regression (WLR) [24] from the common logarithms of theoretical viral loads $\left(\log _{10} \mathrm{VLt}\right)$ and ratios of HIV- 1 and IC fluorescence signals $\left(\log _{10} R\right)$. HIV-1 RNA concentrations of transcripts and samples were estimated by interpolating $\log _{10} R$ in the calibration curve.

2.8. Determination of the In-House qRT-PCR Limit of Detection. The $95 \%$ detection limit (LoD) or the sensitivity of the in-house qRT-PCR assay was assessed on dilution series of a WHO IS 97/656 (NIBSC, South Mimms, Potters Bar, Hertfordshire, UK). Each vial of the HIV-1 standard (subtype B) was reconstituted in $1 \mathrm{~mL}$ of ultrapure water as instructed by the NIBSC to yield a solution containing $100000 \mathrm{IU} / \mathrm{mL}$ of HIV-1 RNA. It was further diluted in HIV-, HCV-, and HBVnegative plasma, resulting in the following concentrations: $50,100,250,500,1000,2500$, and $5000 \mathrm{IU} / \mathrm{mL}$. The number of replicas tested varied from 5 to 15 , and they were run in different days with different reagent lots and operators. A HIV-, HCV-, and HBV-negative cryosupernatant was included, as a negative control, in each run of the assay. We employed the same transcripts and assay conditions that were used in Section 2.6.5. A positive result was considered when the sample fluorescence value was three-fold the fluorescence value of the negative control. The LoD was estimated by Probit analysis $[9,11,25,26]$, using SPSS version 9.0.

2.9. Analysis of the Correlation between the In-House qRT-PCR and NucliSens EasyQ Assays. We analyzed the correlation between our in-house qRT-PCR assay and the commercial NucliSens EasyQ HIV-1 v1.1 assay (bioMerieux, Boxtel, The Netherlands) using linear regression analysis. The quantified values of 14 clinical plasma samples from antiretroviral drugnaïve and treatment-experienced patients were obtained from the "Pedro Kourí" Tropical Medicine Institute (Havana, Cuba), using the NucliSens EasyQ assay. We employed the same transcripts and assay conditions that were used in Section 2.6.5.

\section{Results and Discussion}

Because of HIV-1 variability, we selected and designed primers and probes for the in-house GRT-PCR assay that were based on a highly conserved LTR region of the HIV-1 genome. Instead of the gag gene, the use of the LTR region extends the spectrum of detectable and quantifiable genotypes beyond that of many current assays that are not accurate for testing "exotic" HIV-1 subtypes found mainly in developing countries [11].

To prevent PCR inhibition from interfering with accurate quantification, we designed a competitive internal control that used the same amplification primers as HIV-1 and was detected by a probe of different sequence composition.

We also optimized reaction chemistry to evaluate the RNA standards and to quantify the IS and HIV-1 samples.

The amplified HIV-1 and IC fragments were purified and cloned into the pGEM-T vector. The presence of each band in the T vector was checked by amplification using the HIV1Q3 and HIV1-Biot-Q4 primers, and the fragment orientation was checked by amplification using the T7 Promoter and HIV1-Biot-Q4 primers. In both cases, we obtained the PCR band at the expected length, indicating the presence and the correct orientation of the HIV-1 and IC fragments into the pGEM-T vector.

The pGEM-HIV 1 and pGEM-IC plasmids were in vitro transcribed, and the resultant HIV-1 and IC transcripts (THIV1 and T-IC, resp.) were purified. Before being diluted in the lysis reagent, an aliquot of the two batches of each transcript was diluted $1: 20$ or $1: 35$ and quantified by measuring the OD at $260 \mathrm{~nm}$. RNA concentration in $\mu \mathrm{g} / \mathrm{mL}$ was obtained (Table 2).

According to McKenna et al. [14], large-scale in vitro transcription of RNA yields varies with the transcript being produced. Expected yields should fall in the range of 200$1000 \mu \mathrm{g} / \mathrm{mL}$ [14]. In one in vitro reaction, ARN concentration was below the lower limit of the expected range because of some loss of sample occurring during the purification step of the T-IC second transcript. This issue has been described by McKenna et al. during the phenol/chloroform extraction of transcripts although they stated that this step is necessary because far greater loss is incurred if the extraction step is omitted [14]. Sample loss during RNA purification, which rather depends on the technical skills of the analyst, allows us to explain the big yield differences obtained among the same transcript batches. In some cases, we obtained RNA yields over the upper limit of the expected RNA concentration range (Table 2). The ratio of absorbance at 260 and $280 \mathrm{~nm}$ (the A260/280 ratio) is frequently used to assess the purity of RNA and DNA preparations. A low A260/280 ratio indicates contamination by proteins [27]. Data presented in Table 2 
TABLE 2: RNA concentration of the HIV-1 and IC transcripts determined by spectrophotometry at $260 \mathrm{~nm}$.

\begin{tabular}{lcccc}
\hline Transcript batch & Dilution factor & OD at $260 \mathrm{~nm}(\mathrm{AU})$ & A260/280 ratio & RNA concentration $(\mu \mathrm{g} / \mathrm{mL})$ \\
\hline T-IC-1 $^{\mathrm{a}}$ & 20 & 0.550 & 1.556 & 440.0 \\
T-IC-1 $^{\text {b }}$ & 20 & 0.793 & 1.614 & 634.4 \\
T-IC-2 $^{\text {a }}$ & 35 & 0.118 & 1.586 & 165.2 \\
T-IC-2 $^{\text {b }}$ & 35 & 0.817 & 1.664 & 1143.8 \\
T-HIV1-1 $^{\text {a }}$ & 35 & 1.163 & 1.687 & 1628.2 \\
T-HIV1-1 $^{\text {b }}$ & 35 & 0.225 & 1.665 & 315.0 \\
T-HIV1-2 $^{\text {a }}$ & 35 & 0.471 & 1.543 & 659.4 \\
T-HIV1-2 $^{\text {b }}$ & 35 & 1.183 & 1.700 & 1656.2 \\
\hline
\end{tabular}

AU: absorbance units.

OD: optical density.

A260/280 ratio: the ratio of absorbance at 260 and $280 \mathrm{~nm}$.

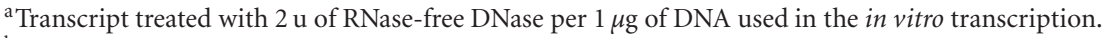

${ }^{\mathrm{b}}$ Transcript treated with $4 \mathrm{u}$ of RNase free DNase-per $1 \mu \mathrm{g}$ of DNA used in the in vitro transcription.

TABLE 3: Evaluation of the presence of specific RNA (RT-PCR signal) and the DNA contamination (PCR signal) of the HIV-1 and IC transcripts.

\begin{tabular}{lccc}
\hline Name & Dilution & Average RT-PCR fluorescence value (FU) \pm SD & Average PCR fluorescence value (FU) \pm SD \\
\hline HIV-1-negative control & - & $4.05 \pm 0.09$ & $3.56 \pm 0.18$ \\
HIV-1-positive control $(R T-P C R)$ & - & $181.9 \pm 2.83$ & - \\
HIV-1-positive control (PCR) & - & - & $117.80 \pm 5.36$ \\
IC-negative control & - & $-3.37 \pm 0.11$ & $3.35 \pm 0.08$ \\
IC-positive control (PCR) & - & $165.92 \pm 2.28$ & $141.81 \pm 2.14$ \\
\hline & $1: 4 \times 10^{3}$ & $181.67 \pm 4.72$ & $31.93 \pm 0.17$ \\
T-HIV1-2 & $1: 4 \times 10^{6}$ & $187.14 \pm 7.57$ & $3.87 \pm 0.24$ \\
& $1: 4 \times 10^{7}$ & $170.72 \pm 8.42$ & $3.87 \pm 0.03$ \\
& $1: 4 \times 10^{8}$ & $171.24 \pm 5.59$ & $4.65 \pm 0.27$ \\
\hline & $1: 4 \times 10^{9}$ & $210.00 \pm 0$ & $3.26 \pm 0.06$ \\
T-IC-2 & $1: 4 \times 10^{3}$ & $107.55 \pm 0.36$ & $3.35 \pm 0.04$ \\
& $1: 4 \times 10^{6}$ & $11.87 \pm 0.38$ & $3.29 \pm 0.01$ \\
& $1: 4 \times 10^{7}$ & $3.43 \pm 0$ & $3.23 \pm 0.11$ \\
\end{tabular}

${ }^{\mathrm{b}}$ Transcript treated with $4 \mathrm{u}$ of RNase-free DNase per $1 \mu \mathrm{g}$ of DNA used in the in vitro transcription.

FU: fluorescence units; SD: standard deviation; IC: internal control.

showed A260/280 ratios from 1.54 to 1.70 . Similar results were obtained by Okamoto and Okabe [27] when they used DEPC-treated water to dissolve RNA for performing the spectrophotometric determinations. The authors stated that DEPC-treated water did not affect the absorbance at $260 \mathrm{~nm}$ but elevated that at $280 \mathrm{~nm}$ [27].

We also evaluated the quality of the HIV-1 and IC transcripts. Transcripts with the highest RNA concentration (T-IC-2 ${ }^{\mathrm{b}}$ and T-HIV1-2 ${ }^{\mathrm{b}}$ ) were 10 -fold serially diluted in lysis reagent from $1: 4 \times 10^{3}$ to $1: 4 \times 10^{9}$. These dilutions were subjected to RT-PCR to evaluate the presence of specific RNA and also subjected to direct PCR without RT in order to test the DNA contamination. Neither PCR signal was obtained for the IC transcript dilutions tested nor for the highest dilutions of the HIV-1 transcript. Specific RT-PCR signals were obtained for both transcripts (Table 3 ).

The use of RNA controls must be absolutely free of plasmid DNA carryover from the in vitro transcription reaction
[28]. In this sense, Hazari et al. [28] developed and evaluated a competitive RT-PCR assay for HCV RNA in serum using transcribed thioRNA as internal control. This internal control RNA was tested for DNA contamination, and no signal was obtained using $1 \mu \mathrm{L}$ of undiluted RNA, containing $10^{8}$ molecules/ $\mu \mathrm{L}$ [28]. Westerman et al. [29] developed a quantitative reverse transcription-polymerase chain reaction for measuring a marker for small cell lung carcinoma. A standard curve was constructed from a complementary RNA (cRNA) of the Human achaete-scute homologue 1 (HASH1) protein that was obtained by in vitro transcription. The authors demonstrated that complete removal of contaminating plasmid was essential for accurate quantification, and this was achieved by overnight incubation with RQ1 DNase One during cRNA purification [29].

In order to develop an in-house qRT-PCR assay for HIV1 RNA and taking into account the very high yields that are obtained in the in vitro transcription reactions [19], 
TABLE 4: Determination of the IC transcript (T-IC-2 ${ }^{\mathrm{b}}$ ) working dilution in a qRT-PCR assay.

\begin{tabular}{|c|c|c|c|c|}
\hline T-IC-2 ${ }^{\mathrm{b}}$ dilution & $r^{2}$ & $b$ & Accuracy IS $10^{3} \mathrm{IU} / \mathrm{mL}\left(\log _{10}\right.$ VLt-Log 10 VLe) & Accuracy IS $10^{4} \mathrm{IU} / \mathrm{mL}\left(\log _{10}\right.$ VLt-Log $\log _{10}$ VLe $)$ \\
\hline $1: 4 \times 10^{4}$ & 0.14 & -0.02 & 26.62 & 65.78 \\
\hline $1: 4 \times 10^{5}$ & 0.87 & 0.31 & -1.87 & -3.05 \\
\hline $1: 4 \times 10^{6}$ & 0.95 & 0.45 & 0.4 & -0.45 \\
\hline $1: 4 \times 10^{7}$ & 0.86 & 0.33 & 2.01 & 0.92 \\
\hline
\end{tabular}

$r^{2}$ : determination coefficient; $b$ : curve slope; IS: HIV-1 RNA international standard (code 97/656); VLt: theoretical viral load; VLe: estimated viral load.

TABLE 5: Determination of the HIV-1 transcript (T-HIV1-2 ${ }^{\mathrm{b}}$ ) RNA concentration in a qRT-PCR assay.

\begin{tabular}{|c|c|c|c|}
\hline Name & T-HIV1-2 ${ }^{\mathrm{b}}$ dilution & HIV-1 RNA (IU/mL) & Mean of the HIV-1 RNA (IU/mL) \\
\hline \multirow{7}{*}{ T-HIV1-2 } & $1: 4 \times 10^{7}$ & Non quantifiable & \multirow{7}{*}{$1.27 E+14$} \\
\hline & $1: 4 \times 10^{8}$ & $8.83 E+13$ & \\
\hline & $1: 4 \times 10^{9}$ & $1.29 E+14$ & \\
\hline & $1: 4 \times 10^{9}$ & $1.50 E+14$ & \\
\hline & $1: 4 \times 10^{10}$ & $1.02 E+14$ & \\
\hline & $1: 4 \times 10^{10}$ & $7.05 E+13$ & \\
\hline & $1: 4 \times 10^{11}$ & $2.21 E+14$ & \\
\hline
\end{tabular}

we used the dilutions of the transcript T-HIV1-2 ${ }^{\mathrm{b}}$ in which DNA signal was not obtained.

We determined the working dilution of the transcript TIC- $2^{\mathrm{b}}$ which acts as internal control of an in-house qRT-PCR assay for HIV-1 RNA. Several 10-fold dilutions of positive HIV-1 human plasma were obtained for constructing a calibration curve $\left(10^{2}\right.$ to $\left.10^{6} \mathrm{IU} / \mathrm{mL}\right)$, and four dilutions of the transcript T-IC- $2^{\mathrm{b}}$ were evaluated.

As observed in Table 4, the dilution required for the IC transcript to work optimally was $1: 4 \times 10^{6}$, in which the $r^{2}$ and the curve slope reached the maximum value. In the selected IC working dilution, the qRT-PCR assay was able to quantify the two IS concentrations $\left(10^{3}\right.$ and $\left.10^{4} \mathrm{IU} / \mathrm{mL}\right)$ accurately, with $\log _{10}$ differences below $\pm 0.5 \log _{10}$ of the expected units (Table 4). As discussed by some authors, a minimally significant change in plasma viremia is considered to be a three-fold or $0.5 \log _{10}$ increase or decrease [30-32].

HIV-1 transcript was quantified so as to introduce it as standard in the qRT-PCR assay. For this purpose, we used the IS $97 / 650$ to obtain the calibration curve and the transcript T-IC- $2^{\text {b }}$ in its working dilution. Transcript T-HIV1-2 ${ }^{\mathrm{b}}$ was 10-fold serially diluted from $1: 4 \times 10^{7}$ to $1: 4 \times 10^{11}$ and quantified using the calibration curve showed in Figure 1.

The RNA concentration estimated for the transcript THIV1-2 ${ }^{\text {b }}$ was similar to the ones obtained by González et al., in which the $\log _{10}$ orders of estimated HCV RNA concentrations were higher than 11 for all transcripts they obtained [19]. In our study, we obtained HIV-1 RNA concentrations about $10^{14} \mathrm{IU} / \mathrm{mL}$ (Table 5), allowing us to use the HIV-1 transcript as standard for quantification purposes in calibration curves that commonly have maximal concentrations with $\log _{10}$ orders between 5 and 9 [19,29].

HIV-1 and IC transcripts were included as standards in an in-house qRT-PCR assay for estimating the HIV1 viral load from plasma samples. The calibration curve was built from the HIV-1 transcript (T-HIV1-2 ${ }^{\mathrm{b}}$ ), and the

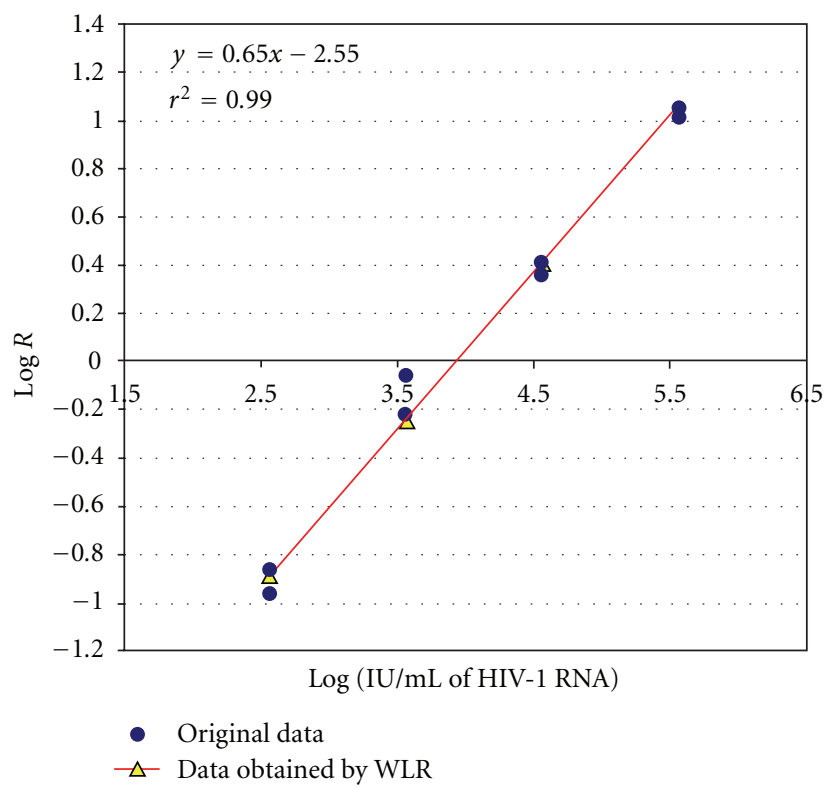

Figure 1: Calibration curve from $3.63 E+02$ to $3.63 E+05 \mathrm{IU} / \mathrm{mL}$, built from the HIV-1 RNA international standard (97/650) in lysis reagent that contains the IC transcript $\left(\mathrm{T}-\mathrm{IC}-2^{\mathrm{b}}\right)$ in its working dilution $\left(1: 4 \times 10^{6}\right)$. LogR: common logarithm of the ratio of HIV1 and IC fluorescence signals. WLR: weighted linear regression.

transcript (T-IC-2 ${ }^{\mathrm{b}}$ ) in its working dilution was used as internal control. Different HIV-1 RNA concentration of the IS and two reference plasma samples with very high viral load were tested to evaluate the accuracy of the assay using these HIV-1 controls.

Figure 2 shows the calibration curve obtained with the inclusion of the HIV-1 and IC transcripts as standards. It was obtained a regression line with an $r^{2}=0.99$. All results were found to be within $\pm 0.5 \log _{10}$ unit of the expected 
TABLE 6: Accuracy of the qRT-PCR assay by using HIV-1 controls and the transcripts as standards.

\begin{tabular}{lccc}
\hline \multirow{2}{*}{ Sample } & \multicolumn{2}{c}{ HIV-1 RNA $(\mathrm{IU} / \mathrm{mL})$} & Log $_{10}$ expected results/actual results \\
\hline IS $(1: 100)$ & Expected results & Actual results & \\
IS $(1: 10)$ & $3.63 E+03^{\mathrm{a}}$ & $3.81 E+03$ & -0.02 \\
IS & $3.63 E+04^{\mathrm{a}}$ & $4.81 E+04$ & -0.12 \\
HIV1-235 & $3.63 E+05^{\mathrm{a}}$ & $5.78 E+05$ & -0.20 \\
HIV1-157 & $1.00 E+06^{\mathrm{b}}$ & $2.33 E+06$ & -0.37 \\
\hline
\end{tabular}

${ }^{\mathrm{a}}$ The value for each IS sample was obtained from dilutions made to the HIV-1 international standard (code 97/650) that contained $363078.05 \mathrm{IU} / \mathrm{mL}$ (reconstituted in $1 \mathrm{~mL}$ of ultrapure water) as instructed by the NIBSC manual.

${ }^{\mathrm{b}}$ The value for each material was determined by the NucliSens EasyQ HIV-1 v1.1 assay (bioMerieux, Boxtel, The Netherlands).

${ }^{c}$ HIV-1 viral loads estimated from the in-house qRT-PCR assay using the HIV-1 (T-HIV1-2 ${ }^{\mathrm{b}}$ ) and IC (T-IC-2 ${ }^{\mathrm{b}}$ ) transcripts as standards.

TABLE 7: Determination of the lower limit detection (LoD) of the in-house qRT-PCR assay.

\begin{tabular}{lccc}
\hline HIV-1 IS RNA concentrations ${ }^{\mathrm{a}}(\mathrm{IU} / \mathrm{mL})$ & Number of replicas tested & Positive results & Positive rate $(\%)$ \\
\hline 5000 & 6 & 6 & 100 \\
2500 & 6 & 11 & 100 \\
1000 & 11 & 14 & 100 \\
500 & 15 & 3 & 93.3 \\
250 & 13 & 1 & 9.1 \\
100 & 11 & 0 & 0 \\
50 & 5 & 0 & 23.1 \\
\hline
\end{tabular}

${ }^{a}$ The HIV-1 IS RNA concentrations were obtained from dilutions made to the HIV-1 international standard (code 97/656) that contained $100000 \mathrm{IU} / \mathrm{mL}$ (reconstituted in $1 \mathrm{~mL}$ of ultrapure water) as instructed by the NIBSC manual.

results (Table 6), which is considered not significant for the quantification assay employed [30-32]. Similar results were obtained by Muller et al., who evaluated five HIV-1 controls from $10^{2}$ to $5 \times 10^{4}$ copies/mL using a quantitative Abbott LCx HIV RNA assay, and all results were found to be within $\pm 0.32 \log _{10}$ unit of the expected results [31]. In order to consider if a biological change in the viral load is significant or not, we show here the intra- and inter-assay variability of the assay using three serum samples with different viral load values. These samples were repeated 24 times in this precision study. Precision is defined as the standard deviation of the log-transformed values [9]. In our study, intra-assay precision was $0.3,0.09$, and $0.03 \log$ units at concentrations $2.7 \times 10^{3}, 2.6 \times 10^{4}$, and $2.0 \times 10^{5} \mathrm{IU} / \mathrm{mL}$, respectively. Interassay precision was $0.43,0.32$, and $0.23 \mathrm{log}$ units at concentrations $2.7 \times 10^{3}, 2.6 \times 10^{4}$, and $2.0 \times 10^{5} \mathrm{IU} / \mathrm{mL}$, respectively. The intra-assay variability reported here was in the range of that obtained for three commercially available HIV-1 viral load assays, with reported values from 0.12 to 0.33 logs [23]. De Mendoza et al. (2005) also reported intraassay precision values of approximately $0.17 \mathrm{log}$ units at HIV1 RNA concentrations above $1000 \mathrm{IU} / \mathrm{mL}$, and $0.26 \mathrm{log}$ units for values lower than $1000 \mathrm{IU} / \mathrm{mL}$ when they evaluated the NucliSens EasyQ HIV-1 v1.1 assay [9].

The percentage of positive results corresponding to each HIV-1 RNA concentration tested by the in-house qRTPCR assay is shown in Table 7. Using Probit analysis, the concentration of HIV-1 RNA with 95\% detection was estimated to be $511.0 \mathrm{IU} / \mathrm{mL}$ ( $95 \%$ confidence interval, 433.4588.6 IU/mL). The LoD for the Amplicor HIV-1 Monitor

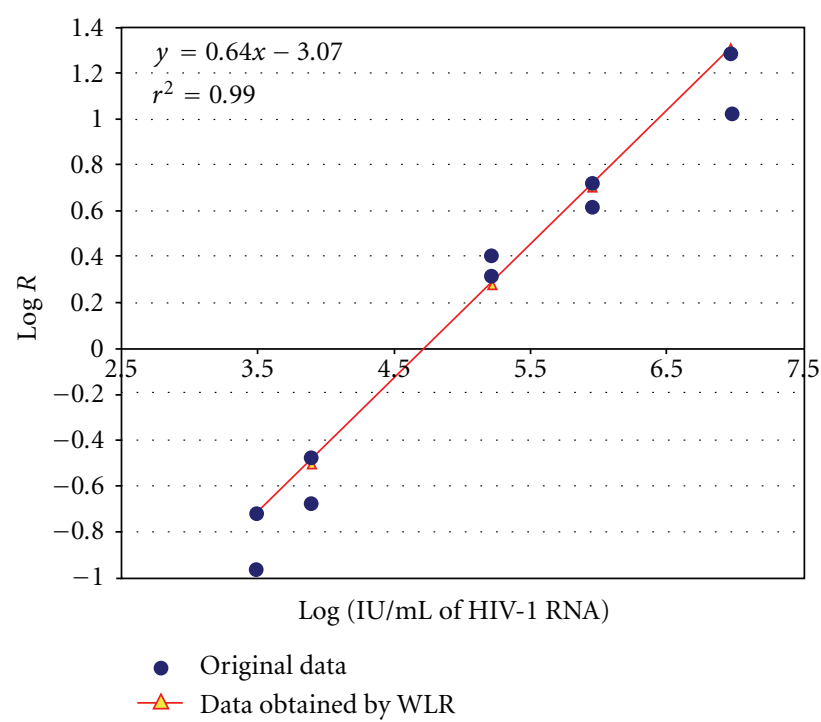

FIGURE 2: Calibration curve $(1.27 E+03,7.76 E+03,1.65 E+05$, $8.95 E+05$, and $9.39 E+06 \mathrm{IU} / \mathrm{mL}$ ) built from the HIV-1 transcript (T-HIV1-2 ${ }^{\mathrm{b}}$ ) in lysis reagent that contains the IC transcript (T-IC$\left.2^{\mathrm{b}}\right)$ in its working dilution $\left(1: 4 \times 10^{6}\right)$. LogR: common logarithm of the ratio of HIV-1 and IC fluorescence signals. WLR: weighted linear regression.

test v1.5 (Roche Diagnostic Systems, Branchburg, NJ, USA) using the standard specimen preparation procedure was 200 copies/mL [33] or $312.5 \mathrm{IU} / \mathrm{mL}$ if we take into account the Roche conversion factor, 0.64 [34]. This Roche test is 


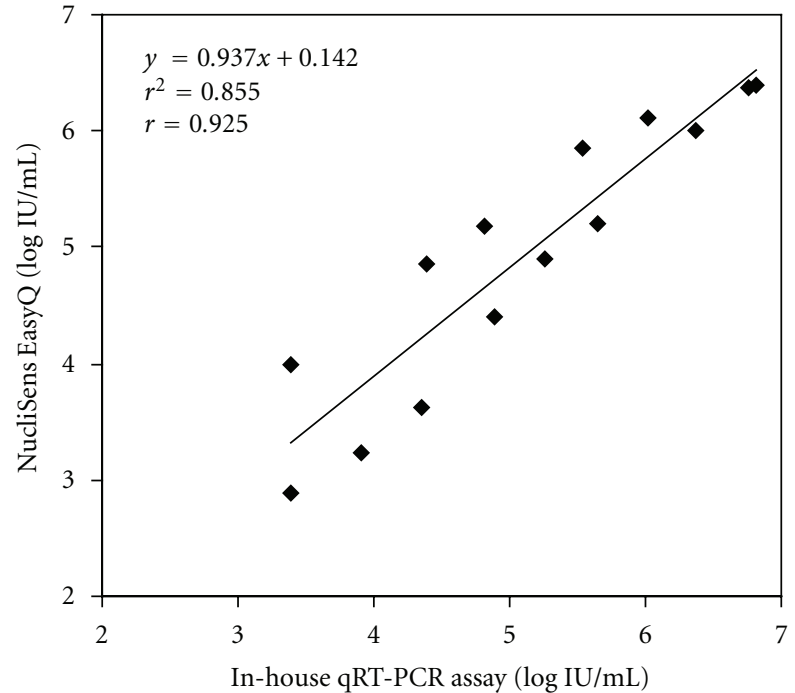

Figure 3: Correlation between the NucliSens EasyQ HIV-1 v1.1 test (bioMerieux, Boxtel, The Netherlands) and the in-house qRTPCR assay, on 14 plasma specimens from HIV-1 infected patients. The solid line represents the identity line, where all determinations should fall if a perfect correlation between the two assays was achieved. $r^{2}$, determination coefficient; $r$, correlation coefficient.

based on a similar assay methodology to that of our in-house qRT-PCR assay.

The sensitivity obtained for our in-house qRT-PCR assay was similar to the one obtained with the NucliSens EasyQ HIV-1 (500.0 IU/mL) using $0.2 \mathrm{~mL}$ of input sample volume $[10,32]$.

The analysis of correlation between our in-house qRTPCR assay and the NucliSens EasyQ HIV-1 test is shown in Figure 3. The correlation between the two assays was high $(r=0.925)$. A similar correlation coefficient $(r=0.91)$ was obtained by Choi et al., who compared the NucliSens EasyQ HIV-1 v1.1 (bioMerieux) and RealTime HIV-1 (Abbott) kits [1]. The correlation coefficient of the NucliSens EasyQ HIV1 kit with the Cobas Amplicor HIV-1 Monitor v1.5 (Roche Diagnostic Systems, Branchburg, NJ, USA) test, which is based on traditional PCR method instead of real-time PCR, was 0.87 [9].

A high correlation between different assays is important because the data on HIV-1 RNA quantitation are collected from various laboratories using different kinds of assay kits nationwide [1]. However, it has been recommended using the same method and also possibly the same laboratory to monitor patients [35].

Human plasma or serum samples can be indistinctly used in our in-house qRT-PCR assay because they were both evaluated, and no significant viral load differences were found between them (data not shown).

It was observed a good linear behavior along the calibration curve built with the transcripts, which reached maximum HIV-1 RNA concentration near $10^{7} \mathrm{IU} / \mathrm{mL}$ or $7 \log _{10}$ (Figure 2). As discussed by Yao et al., the ability to quantify HIV-1 RNA over a $5 \log _{10}$ is important in this kind of assays that are used to evaluate a variety of patient populations with a wide range of viral loads. This is an important asset when a normal clinical laboratory test run includes samples from newly diagnosed untreated patients, who generally have a higher viral load than chronic HIV-1 infected adults. This feature also eliminates the need for reflex repeat testing, improves turnaround time for results, and is associated with significant savings in both technical time and reagent costs [32].

In summary, the HIV-1 and IC transcripts were obtained with the required quality to be used as standards for quantification purposes, considering also the advantage of their long-term stability when stored in the lysis reagent $[20,21]$. It was obtained a high correlation between our assay and a commercial one. On the other hand, one of the major benefits of our method is cost reduction. Commercially assays are currently offered, even in developing countries, at prices of approximately US $\$ 50-\$ 100$ per test $[10,11]$. For our inhouse HIV-1 viral load assay, the net price would be reduced considerably.

\section{Abbreviations}

\begin{tabular}{|c|c|}
\hline RNA: & Ribonucleic acid \\
\hline DNA: & Desoxyribonucleic acid \\
\hline cDNA: & Complementary DNA \\
\hline RT: & Reverse transcription \\
\hline PCR: & Polymerase chain reaction \\
\hline RT-PCR: & $\begin{array}{l}\text { Reverse transcription-polymerase chain } \\
\text { reaction }\end{array}$ \\
\hline qRT-PCR: & Quantitative competitive RT-PCR \\
\hline IC: & Internal control \\
\hline HCV: & Hepatitis $\mathrm{C}$ virus \\
\hline HBV: & Hepatitis B virus \\
\hline HIV-1: & Human immunodeficiency virus type-1 \\
\hline Bp: & Base pairs \\
\hline WLR: & Weighted linear regression \\
\hline dNTP: & Desoxribonucleotides \\
\hline rNTP: & Ribonucleotides \\
\hline WHO: & World Health Organization \\
\hline IS: & WHO international standard \\
\hline DEPC: & Diethylpyrocarbonate \\
\hline LTR: & Long terminal repeat \\
\hline OD: & Optical density \\
\hline$r^{2}:$ & Determination coefficient \\
\hline$b:$ & Curve slope \\
\hline NIBSC: & $\begin{array}{l}\text { National Institute for Biological Standards } \\
\text { and Control }\end{array}$ \\
\hline VLt: & Theoretical viral load \\
\hline VLe: & Estimated viral load \\
\hline$R:$ & Ratio of HIV-1 and IC fluorescence signals \\
\hline $\log _{10}$ VLt: & Common logarithm of VLt \\
\hline $\log _{10} R:$ & $\begin{array}{l}\text { Common logarithm of the ratio of HIV-1 } \\
\text { and IC fluorescence signals }\end{array}$ \\
\hline FU: & Fluorescent units \\
\hline AU: & Absorbance units \\
\hline SD: & Standard deviation \\
\hline LoD: & $95 \%$ detection limit. \\
\hline
\end{tabular}




\section{Acknowledgments}

The authors thank Jorge Pérez Ávila., from the "Pedro Kouri" Tropical Medicine Institute (Havana, Cuba) for supplying the clinical samples that were quantified with the commercial NucliSens EasyQ HIV-1 v1.1 assay (bioMerieux) in such institute. They also thank Ricardo Silva Rodríguez. (Center for Genetic Engineering and Biotechnology, Havana, Cuba) for his valuable help in revising the English paper.

\section{References}

[1] J. Y. Choi, E. J. Kim, H. J. Rho et al., "Evaluation of the NucliSens EasyQ HIV-1 v1.1 and RealTime HIV-1 kits for quantitation of HIV-1 RNA in plasma," Journal of Virological Methods, vol. 161, no. 1, pp. 7-11, 2009.

[2] D. D. Ho, "Dynamics of HIV-1 replication in vivo," Journal of Clinical Investigation, vol. 99, no. 11, pp. 2565-2567, 1997.

[3] V. Simon and D. D. Ho, "HIV-1 dynamics in vivo: implications for therapy," Nature Reviews Microbiology, vol. 1, no. 3, pp. 181-190, 2003.

[4] D. V. Havlir and D. D. Richman, "Viral dynamics of HIV: implications for drug development and therapeutic strategies," Annals of Internal Medicine, vol. 124, no. 11, pp. 984-994, 1996.

[5] M. E. Quiñones-Mateu and E. J. Arts, "Fitness of drug resistant HIV-1: methodology and clinical implications," Drug Resistance Updates, vol. 5, no. 6, pp. 224-233, 2002.

[6] J. B. Peter and J. S. Sevall, "Molecular-based methods for quantifying HIV viral load," AIDS Patient Care and STDs, vol. 18, no. 2, pp. 75-79, 2004.

[7] A. Katsoulidou, M. Petrodaskalaki, V. Sypsa et al., "Evaluation of the clinical sensitivity for the quantification of human immunodeficiency virus type 1 RNA in plasma: comparison of the new COBAS TaqMan HIV-1 with three current HIV-RNA assays-LCx HIV RNA quantitative, VERSANT HIV-1 RNA 3.0 (bDNA) and COBAS AMPLICOR HIV-1 Monitor v1.5," Journal of Virological Methods, vol. 131, no. 2, pp. 168-174, 2006.

[8] C. A. Heid, J. Stevens, K. J. Livak, and P. M. Williams, "Real time quantitative PCR," Genome Research, vol. 6, no. 10, pp. 986-994, 1996.

[9] C. De Mendoza, M. Koppelman, B. Montès et al., "Multicenter evaluation of the NucliSens EasyQ HIV-1 v1.1 assay for the quantitative detection of HIV-1 RNA in plasma," Journal of Virological Methods, vol. 127, no. 1, pp. 54-59, 2005.

[10] S. A. Fiscus, B. Cheng, S. M. Crowe et al., "HIV-1 viral load assays for resource-limited settings," PLoS Medicine, vol. 3, no. 10, pp. 1743-1750, 2006.

[11] C. Drosten, M. Panning, J. F. Drexler et al., "Ultrasensitive monitoring of HIV-1 viral load by a low-cost real-time reverse transcription-PCR assay with internal control for the 5 ' long terminal repeat domain," Clinical Chemistry, vol. 52, no. 7, pp. 1258-1266, 2006.

[12] A. Telenti, P. Imboden, and D. Germann, "Competitive polymerase chain reaction using an internal standard: application to the quantitation of viral DNA," Journal of Virological Methods, vol. 39, no. 3, pp. 259-268, 1992.

[13] S. Gallo, M. Furler, and R. Sigel, "In vitro transcription and purification of RNAs of different size," Chimia, vol. 59, no. 11, pp. 812-816, 2005.
[14] S. A. McKenna, I. Kim, E. V. Puglisi et al., "Purification and characterization of transcribed RNAs using gel filtration chromatography," Nature Protocols, vol. 2, no. 12, pp. 32703277, 2007.

[15] M. P. De Baar, M. W. Van Dooren, E. De Rooij et al., "Single rapid real-time monitored isothermal RNA amplification assay for quantification of human immunodeficiency virus type 1 isolates from groups M, N, and O," Journal of Clinical Microbiology, vol. 39, no. 4, pp. 1378-1384, 2001.

[16] “pGEM ${ }^{\circledR}$-T y pGEM ${ }^{\circledR}$-T Easy Vectors Systems,” Technical Manual, Promega, Madison, Wis, USA, 2007, http://www .promega.com.

[17] P. Chomczynski, "A reagent for the single-step simultaneous isolation of RNA, DNA and proteins from cell and tissue samples," BioTechniques, vol. 15, no. 3, pp. 532-535, 1993.

[18] I. González, A. Armas, I. García, and Y. González, "Homemade viral RNA isolation protocol using silica columns: a comparison of four protocols," Analytical Biochemistry, vol. 360, no. 1, pp. 148-150, 2007.

[19] I. González, I. García, A. Armas et al., "Scaling up in vitro transcription synthesis of RNA standards for competitive quantitative RT-PCR: looking for bigger yields," Analytical Biochemistry, vol. 385, no. 1, pp. 179-181, 2009.

[20] I. González, A. Armas, I. García et al., "Composición estabilizadora de ácidos nucleicos para su conservación a $4{ }^{\circ} \mathrm{C}$ por períodos prolongados," Cuban patent application 23588, September 2010.

[21] I. González, A. Armas, Y. Perea et al., "Long-term conservation of HCV RNA at $4{ }^{\circ} \mathrm{C}$ using a new RNA stabilizing solution," Journal of Virological Methods, vol. 168, no. 1-2, pp. 207-211, 2010.

[22] I. González, Y. J. González, A. Armas et al., "Validation of a nested PCR assay UMELOSA HCV CUALITATIVO for the detection of hepatitis C virus," Biologicals, vol. 31, no. 1, pp. 55-61, 2003.

[23] Y. Schmitt, "Performance characteristics of quantification assays for human immunodeficiency virus type 1 RNA," Journal of Clinical Virology, vol. 20, no. 1-2, pp. 31-33, 2001.

[24] D.C. Montgomery, Design and Analysis of Experiments, John Wiley, New York, NY, USA, 1991.

[25] A. M. Caliendo, J. Ingersoll, A. M. Green, F. S. Nolte, and K. A. Easley, "Comparison of the sensitivities and viral load values of the AMPLICOR HIV-1 MONITOR version 1.0 and 1.5 tests," Journal of Clinical Microbiology, vol. 42, no. 11, pp. 5392-5393, 2004.

[26] M. José, R. Gajardo, and J. I. Jorquera, "Stability of HCV, HIV1 and HBV nucleic acids in plasma samples under long-term storage," Biologicals, vol. 33, no. 1, pp. 9-16, 2005.

[27] T. Okamoto and S. Okabe, "Ultraviolet absorbance at 260 and $280 \mathrm{~nm}$ in RNA measurement is dependent on measurement solution," International Journal of Molecular Medicine, vol. 5, no. 6, pp. 657-659, 2000.

[28] S. Hazari, S. K. Acharya, and S. K. Panda, "Development and evaluation of a quantitative competitive reverse transcription polymerase chain reaction (RT-PCR) for hepatitis $\mathrm{C}$ virus RNA in serum using transcribed thio-RNA as internal control," Journal of Virological Methods, vol. 116, no. 1, pp. 45-54, 2004.

[29] B. A. Westerman, S. Neijenhuis, A. Poutsma et al., "Quantitative reverse transcription-polymerase chain reaction measurement of HASH1 (ASCL1), a marker for small cell lung carcinomas with neuroendocrine features," Clinical Cancer Research, vol. 8, no. 4, pp. 1082-1086, 2002. 
[30] C. A. Gleaves, J. Welle, M. Campbell et al., "Multicenter evaluation of the Bayer VERSANT ${ }^{\mathrm{TM}}$ HIV-1 RNA 3.0 assay: analytical and clinical performance," Journal of Clinical Virology, vol. 25, no. 2, pp. 205-216, 2002.

[31] Z. Muller, E. Stelzl, M. Bozic, J. Haas, E. Marth, and H. H. Kessler, "Evaluation of automated sample preparation and quantitative PCR LCx assay for determination of human immunodeficiency virus type 1 RNA," Journal of Clinical Microbiology, vol. 42, no. 4, pp. 1439-1443, 2004.

[32] J. Yao, Z. Liu, L. S. Ko, G. Pan, and Y. Jiang, "Quantitative detection of HIV-1 RNA using NucliSens EasyQ HIV-1 assay," Journal of Virological Methods, vol. 129, no. 1, pp. 40-46, 2005.

[33] K. Triques, J. Coste, J. L. Perret et al., "Efficiencies of four versions of the AMPLICOR HIV-1 MONITOR Test for quantification of different subtypes of human immunodeficiency virus type 1," Journal of Clinical Microbiology, vol. 37, no. 1, pp. 110-116, 1999.

[34] P. Palla, M. L. Vatteroni, L. Vacri, F. Maggi, and U. Baicchi, "HIV-1 NAT minipool during the pre-seroconversion window period: detection of a repeat blood donor," Vox Sanguinis, vol. 90, no. 1, pp. 59-62, 2006.

[35] S. M. Hammer, J. J. Eron, P. Reiss Jr. et al., “Antiretroviral treatment of adult HIV infection: 2008 recommendations of the International AIDS Society-USA panel," Journal of the American Medical Association, vol. 300, no. 5, pp. 555-570, 2008. 

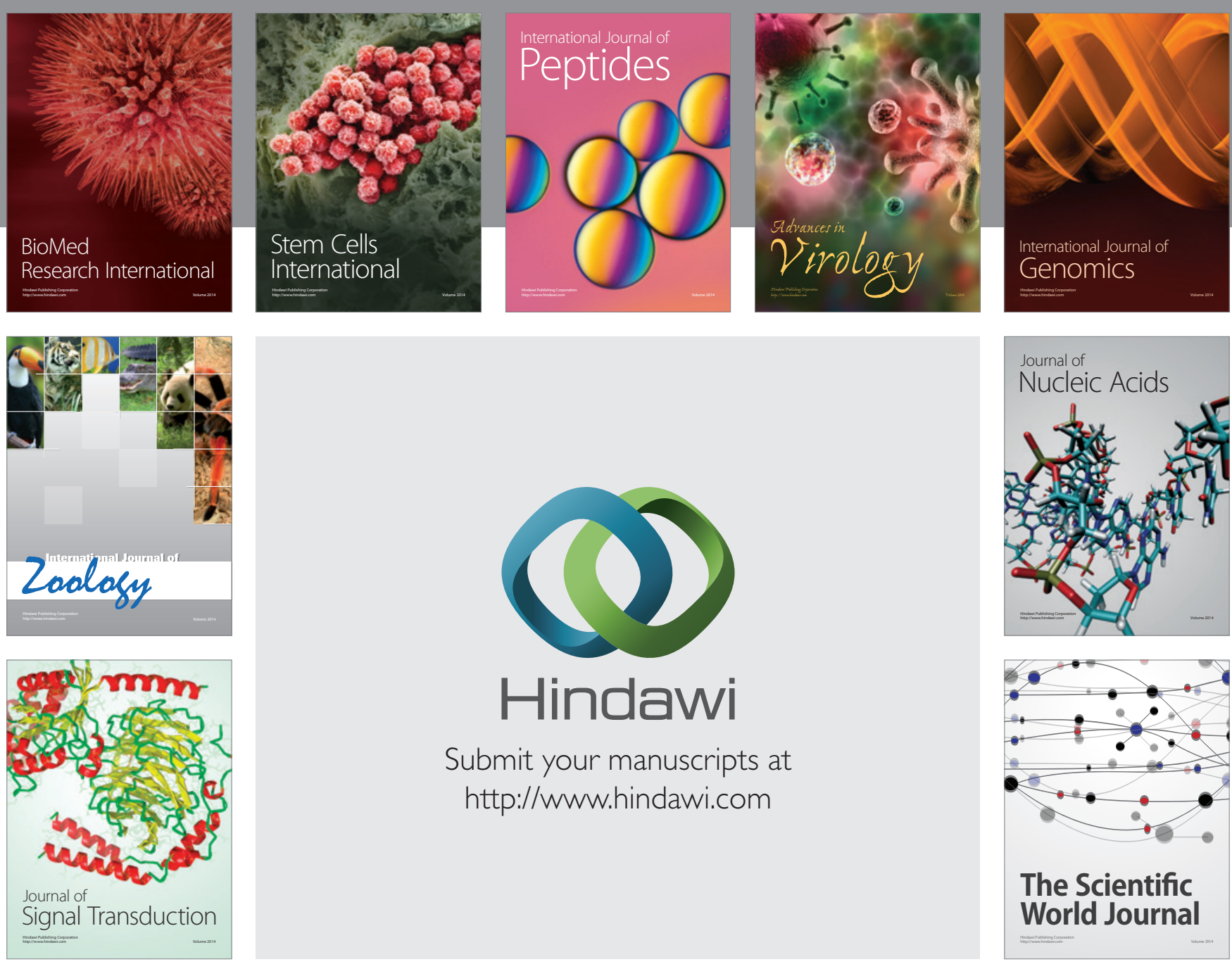

Submit your manuscripts at

http://www.hindawi.com
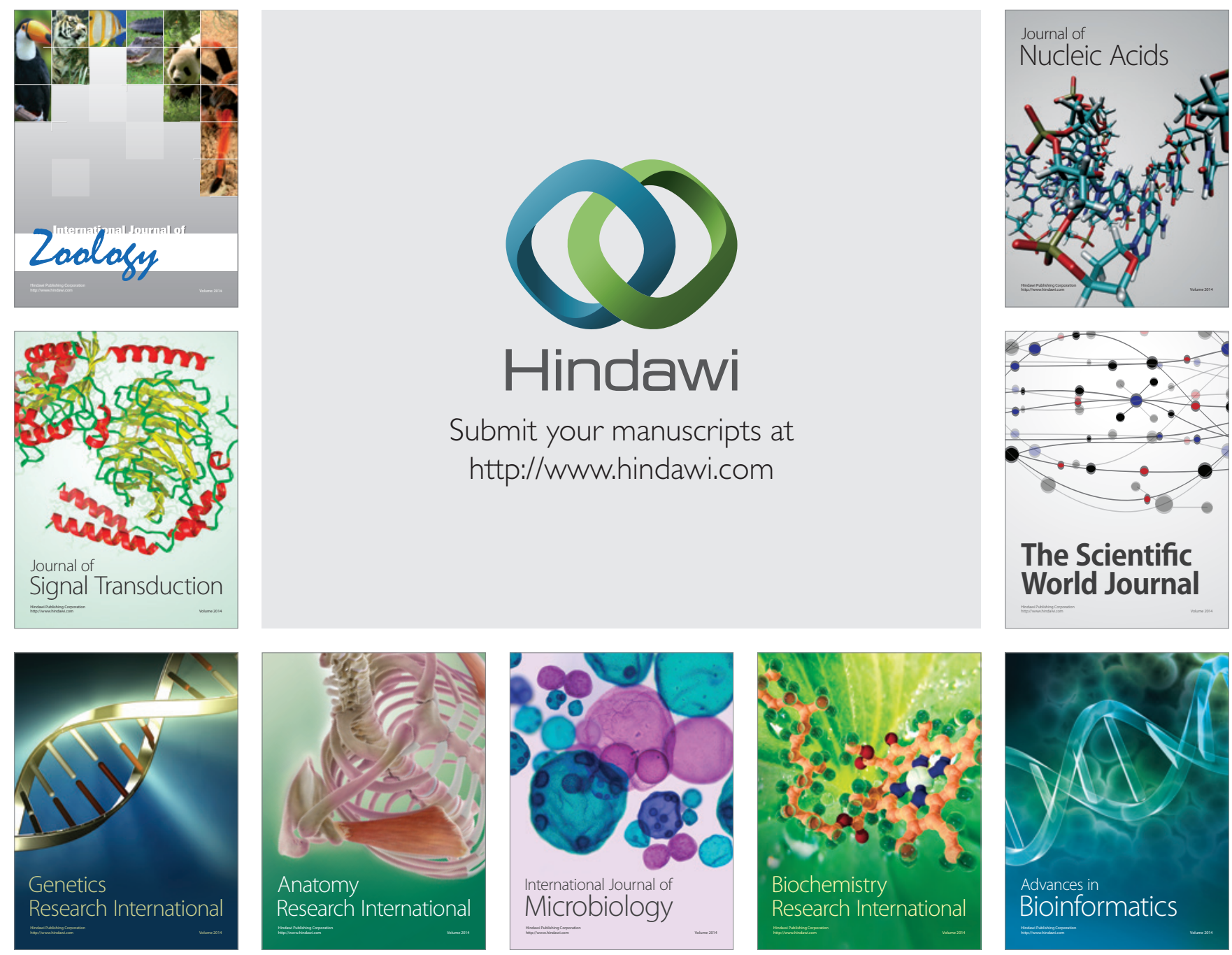

The Scientific World Journal
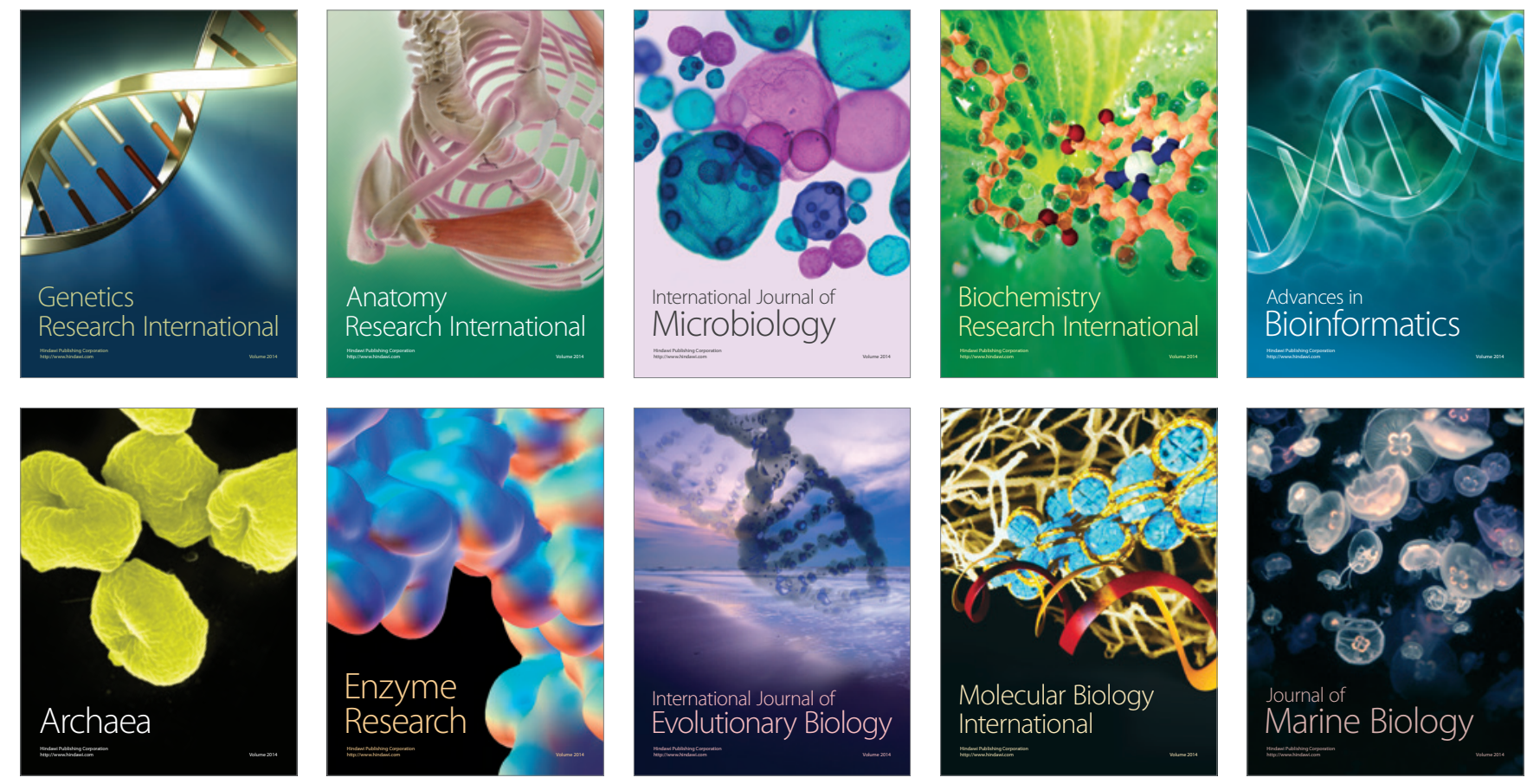